\title{
Rate of Cesarean Delivery, by Maternal Prepregnancy Body Mass Index Category* — United States, 2020
}

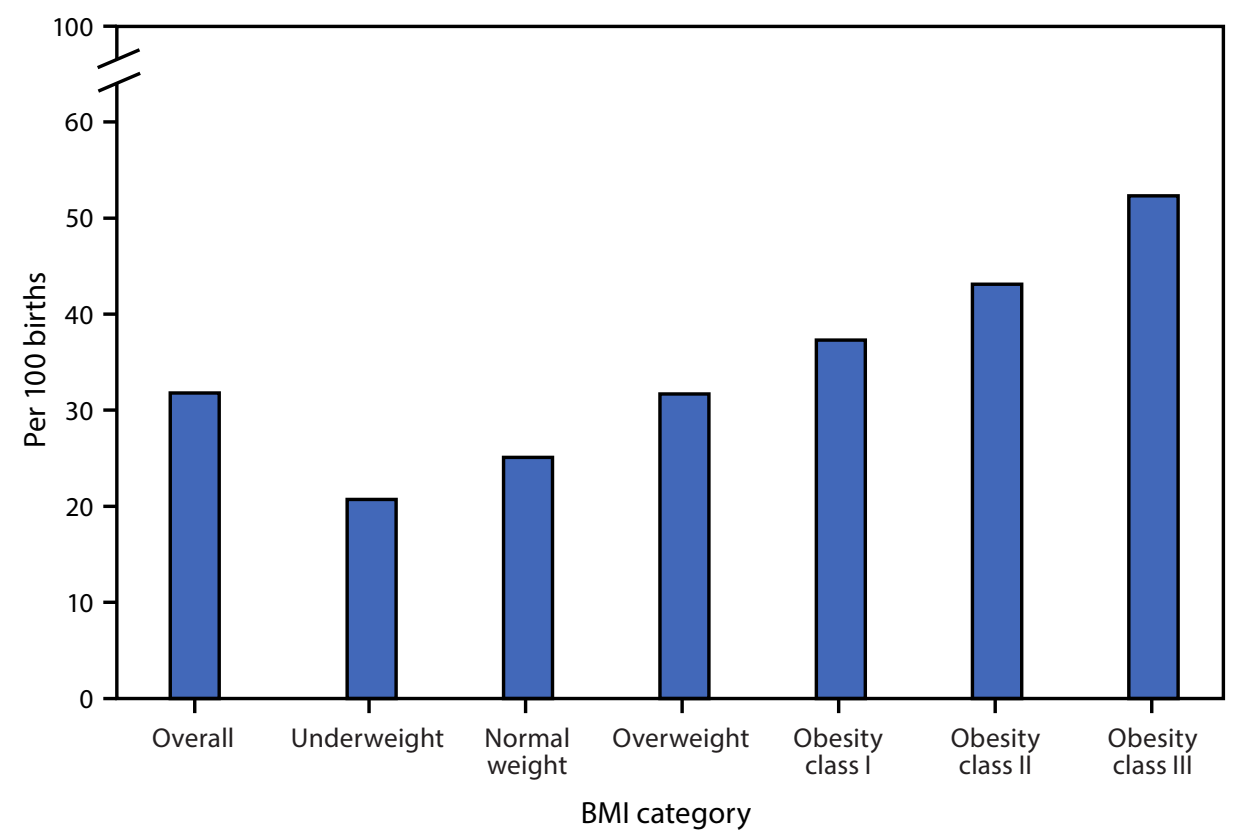

Abbreviation: $\mathrm{BMI}=$ body mass index.

* $\mathrm{BMI}=$ weight $(\mathrm{kg}) /$ height $\left(\mathrm{m}^{2}\right)$. BMl categories are underweight $(<18.5)$, normal weight $(18.5-24.9)$, overweight (25.0-29.9), obesity class I (30.0-34.9), obesity class II (35.0-35.9), and obesity class III ( $\geq 40.0)$.

In 2020,31.8\% of live births were to women who had a cesarean delivery. The rate of cesarean delivery was lowest for women who were underweight before pregnancy (20.7\%); the rate rose steadily as BMI increased to obesity class III (52.3\%). One quarter (25.1\%) of women of normal weight had a cesarean delivery.

Sources: National Vital Statistics System, natality file. https://wonder.cdc.gov/natality-expanded-current.html; Defining adult overweight and obesity. https://www.cdc.gov/obesity/adult/defining.html\#: :text=Class\%203\%3A\%20BMI\%20of\%2040\%20or\%20higher.\%20Class,body\%20 fatness\%20or\%20the\%20health\%20of\%20an\%20individual

Reported by: Isabelle Horon, DrPH, ibh3@cdc.gov, 301-458-4555. 